\title{
Dimensions of Parental Involvement as Antecedents of Attitude towards Reading English (EFL): A Case Study from Omani Basic Education Schools, Cycle One (1-4)
}

\author{
Harith Nasser Khalaf Al Bahri ${ }^{1, *}$, Shaik Abdul Malik Mohamed Ismail ${ }^{1}$, Shuki Osman ${ }^{1}$, \\ Muhammad Khaleel $^{2}$ \\ ${ }^{1}$ School of Education, University Sains Malaysia, Malaysia \\ ${ }^{2}$ School of Management, University Sains Malaysia, Malaysia
}

Received October 28, 2019; Revised January 2, 2020; Accepted January 5, 2020

Copyright $\subseteq 2020$ by authors, all rights reserved. Authors agree that this article remains permanently open access under the terms of the Creative Commons Attribution License 4.0 International License

\begin{abstract}
The study examined the relationship between parental involvement and attitude towards reading English in the Sultanate of Oman. This study adopted the two-dimensional approach of parental involvement, using encouragement from parents and building positive modelling. The study involved cycle one student in Basic Education level specifically, in grade. The parents who participated were from Batinah South Governorate. They voluntarily completed the 24-items questionnaire regarding their involvement towards their children's reading in English. A total number of 413 questionnaire were completed and analysed quantitatively using PLS-SEM. The major findings of the study revealed that both of the dimensions of parental involvement have positive effect on the students' reading attitude. Specifically, the predictors of attitude towards reading indicated that Parental Encouragement $(\beta=0.48, p<0.01)$ is positively related to attitude towards reading. While, Positive Modelling ( $\beta=0.463, p<0.01$ ) is positively related to attitude towards reading; both explaining $78.6 \%$ of variance on attitude towards reading. This study extends the body of knowledge especially in the Middle East region (Sultanate of Oman) where the first language is Arabic. To the best of the authors' knowledge, this was the only study about reading in English particularly looking at the attitude towards reading in two dimensions manner and was the first of its kind among cycle one students in Basic Education level in the Sultanate of Oman.
\end{abstract}

Keywords Parental Involvement, Encouragement, Building Positive Modelling, Attitude towards Reading

\section{Introduction}

In early childhood, the behaviour of children can be observed that shows their involvement in reading [1]. These relatively stable dispositional behaviours towards activities associated with reading and books have been shown to be related to early literacy skills such as vocabulary, knowledge of print conventions [2], letter and word knowledge [3] and academic accomplishment [4]. These links can be clarified by the affective behaviours, commitments, dedications and awareness in response to their attitude towards reading [5], that, in turn, is vital for learning.

Students desire to read is linked to elements of reading behaviour, such as reading frequency, and this reading pattern adds to the advancement of their reading abilities [6, 7]. Children's Reading motivation consists of multiple components`, including attitude`, behaviours`, beliefs`, interest and participation in reading for a variety of purposes [5, 8-10]. Although it is recognized that a number of components can influence the motive of reading such as readers' dependency mostly on reading attitudes and interest in reading. Typically, interest and attitude are likely to be seen as affective in nature. They are precursors of behaviour and are obtained from personal experience.

The Progress in International Reading Literacy Study (PIRLS) defines students' attitudes towards reading as 'students' views on reading for enjoyment and appreciating books' (PIRLS 2006). Earlier, Alexander and Filler's [12] have defined attitude towards reading as "a system of feelings related to reading which causes the learner to approach or avoid a reading situation”, Saito, Garza [13] claimed attitude towards reading as "an individual's feelings about reading, caused learner to approach or avoid 
a reading situation”. Beck [14] observed attitude as combination of positive and negative feelings towards reading. Similarly, McKenna, Kear [15] conducted a large-scale study on students between $1^{\text {st }}$ to $6^{\text {th }}$ Grade in United States, using the visual Likert rating scale, which consists of issues about emotions among kids in readings. The study also had gendered perspective to compare male and female pupils. They considered that attitude represents the continuation of positive to negative emotions in reading.

A positive attitude of reading benefits the student in several areas. They will not exhaust themselves in fulfilling their classroom assignments. Children who like to read often can readily understand the purpose of literature and can readily learn moral advice from the literature they reads. In line to this, Beck [14] added that children's attitude towards reading could have a deep effect on academic achievement. As Lim, Bong [16] points to, the readership of students can influence reading performance and the student willingly reads for information and pleasure. These reading activities improves the knowledge of the child in every aspect of life.

Previous research trends on attitudes mainly focused on the sex-related differences, such as in the US, McKenna, Kear [15] demonstrated more positive reading attitudes of females than males across primary school grades 1-6. Ozturk, Hill [17] conducted research on the reading attitudes of $1^{\text {st }}$ to $5^{\text {th }}$ grade students in suburban Adelaide and found that parental gendered view literacy favour to female students limits the male's attitude towards reading. Similarly, [18] used McKenna and al. tool (1995), which examines reading attitudes of children. Their results show that female pupils have recorded considerably more favourable reading attitude than male pupils. One of the major studies on reading attitude of the students reveals a negative relationship between the attitude towards reading and reading ability of the students.

\subsection{Parental Involvement}

Parents are children's first and primary teachers [19]. Recently, parents have been recognized for the crucial role they play in establishing the foundation of their child's reading ability. Faires, Nichols [20] stated that parents provide the primary foundations for later literacy success, and they should provide experiences to ensure an increase in their children's knowledge of reading.

Society in general, and educational researchers in particular, have long been interested in the positive effect that parental involvement may have on students' academic achievement [21-24]. The perception that parental involvement has positive effect on students' academic success is so intuitively appealing that policy makers, school board administrators, teachers, parents (ECS Distribution and even students themselves have agreed that parental involvement is critical for children's academic success $[20,22,25,26]$.
Past researchers [27] put forth a comprehensive theoretical framework about parental involvement. Their theoretical conceptualization about parental involvement focuses on three main issues: (1) why parents become involved in their children's education, (2) how parents choose specific types of involvement, and (3) why parental involvement has positive influence on students' education outcomes. This theoretical framework promises to be more than a typology for parental involvement, because it not only deals with specific types of parental involvement, but more importantly, it attempts to explain why parents choose to be involved, and what are the mechanisms through which parental involvement exert positive influence on students' educational outcomes. Although the theoretical model is promising, it is still unclear how the major elements in this model can be operationally defined and measured empirically.

Although parental involvement is often simplistically perceived as unidimensional, in reality, it is probably better to conceptualize this construct as being multifaceted in nature, because parental involvement subsumes a wide variety of parental behavioural patterns and parenting practices $[28,29]$. Such an approach has been adopted in several recent empirical studies [25].

Therefore, the above debate has two types of parental participation in reading: The role of parents to encourage their kids to read, and their role in modelling positive reading attitude. The first method can be viewed direct and the second one can be classified as an indirect manner to foster reading among children. There is no exact definition of the dimensions of parental involvement. Based on [25] encouragement refers to the motivation provided by the parents to their children for reading books by bringing them to library and giving books as a gift. Positive modelling refers to action shown by the parents to their children to motivate them for reading. This study extends the knowledge on parental involvement by examining the factor with two-dimensional approach.

\subsection{Purpose of the Study}

The current study investigates the relationships between the two dimensions of parental involvement (i.e. encouraging, building positive modelling) on the attitude towards reading English as a foreign language. The study is conducted among Cycle one students of Basic Education in one governate in the Sultanate of Oman; namely Batinah south Governorate Oman. Past literature shows that there is only one study conducted on the validation of parental involvement by ALazri [25] in the context of Sultanate of Oman. This study extends the body of knowledge by examining the role of parental involvement on attitude towards reading English.

\subsection{Methodology}

This survey was conducted in 19 schools from six 
Wilayat (districts) in Al Batinah South Governorate, Oman. Initially, children from grade 4 were selected for the participation and their parents were contacted. Information was sent to 500 parents and positive replies were received from 413 parents. Therefore, 413 parents and children were selected for this cross-sectional study.

\section{Measures}

\subsection{Attitude towards Reading}

In this study, children's attitudes towards reading were measured by the LAS, which was adapted from a reading attitude scale developed by McKenna and Kear (1990). That was because their scale had an attention-getting, student-friendly pictorial response format. McKenna and Kear [30] suggest that a pictorial format naturally appeals to children and is comprehensible from the early years. The children were presented with pictures of children engaged in reading-related activities with a sad face, a neutral face and a happy face. The researcher asked, 'This child is reading a book alone, how would you feel when you read alone?' and pointed to the child with the sad, neutral, or happy face. Each item was given a score between 1 and 3, in which 1 = very happy 2 = Slightly happy $3=$ Slightly sad 4= very sad.

\subsection{Parental Involvement}

In order to assess Omani parental involvement in reading, the researcher adopted questionnaire from Alazri [25]. Khalid, Khaleel [31] pointed out that the questionnaire method is the best way to collect data about human attitudes and behaviours because the form of any questionnaire does not usually contain the names of participants, which will encourage and stimulate the respondents to give valid and reliable information. The questionnaire of parental involvement in reading included 24 items that employed five Likert responses (5=very much/ $4=$ much $/ 3=$ slightly $/ 2=$ little/ $1=$ very little). The Alpha coefficients for this questionnaire ranged from .85 to .92 for Omani fathers and mothers respectively.

\section{Results}

Initially, data were analysed using SPSS for Windows SPSS version 24. Later, Partial Least Squares Structural Equations Modelling (PLS-SEM, see Hair et al., 2014) was used to analyse the path model. Smart PLS v2.0 software [32] was used to test the proposed hypotheses (see explanation by Hair et al., 2014). PLS-SEM is a second-generation data analysis technique that analyses and explains research model with many variables and constructs. PLS-SEM is a variance-based approach [33] that enables the instantaneous analysis of up to 200 indicator variables, allowing the examination of extensive interactions among independent, dependent, mediator and moderator variables [34].

\subsection{Measurement Model}

To evaluate the measurement model two types of validity were examined, the first being convergent validity and second being discriminant validity. Convergent validity of the measurement model is typically determined by examining the loadings, average variance extracted (AVE) and the composite reliability (CR). The loadings of the individual item were all higher than 0.7. The composite reliabilities were all higher than 0.7 and the AVE values were also higher than the benchmark value 0.5 . As shown in Table 1.

The discriminant validity of the measures (the degree to which items differentiate among constructs or measure distinct concepts) was examined by following the [35] criterion of comparing the correlations between constructs and the square root of the AVE for that construct (see Table 2). In sum, both convergent and discriminant validity of the measures in this study were established. Further to assess the multicollinearity VIF is used. The cut-off value for VIF is 5 . In this study, all the values are below 5 which means there is no multicollinearity issue in the data. As shown in Table 2 . 
Table 1. Measurement Model of the Variables

\begin{tabular}{|c|c|c|c|c|c|}
\hline Variable & Items & Loading & Cronbach's Alpha & CR & AVE \\
\hline \multirow[t]{20}{*}{ ATTITUDE } & AT1 & 0.71 & 0.958 & 0.962 & 0.559 \\
\hline & AT2 & 0.728 & & & \\
\hline & AT3 & 0.803 & & & \\
\hline & AT4 & 0.791 & & & \\
\hline & AT5 & 0.804 & & & \\
\hline & AT6 & 0.699 & & & \\
\hline & AT7 & 0.732 & & & \\
\hline & AT8 & 0.798 & & & \\
\hline & AT9 & 0.767 & & & \\
\hline & AT10 & 0.779 & & & \\
\hline & AT11 & 0.722 & & & \\
\hline & AT12 & 0.723 & & & \\
\hline & AT13 & 0.796 & & & \\
\hline & AT14 & 0.728 & & & \\
\hline & AT15 & 0.743 & & & \\
\hline & AT16 & 0.673 & & & \\
\hline & AT17 & 0.737 & & & \\
\hline & AT18 & 0.736 & & & \\
\hline & AT19 & 0.766 & & & \\
\hline & AT20 & 0.697 & & & \\
\hline \multirow[t]{12}{*}{ ENCOURAGEMENT } & PE1 & 0.789 & 0.945 & 0.952 & 0.623 \\
\hline & PE2 & 0.773 & & & \\
\hline & PE3 & 0.737 & & & \\
\hline & PE4 & 0.798 & & & \\
\hline & PE5 & 0.783 & & & \\
\hline & PE6 & 0.783 & & & \\
\hline & PE7 & 0.801 & & & \\
\hline & PE8 & 0.802 & & & \\
\hline & PE9 & 0.809 & & & \\
\hline & PE10 & 0.813 & & & \\
\hline & PE11 & 0.817 & & & \\
\hline & PE12 & 0.763 & & & \\
\hline \multirow[t]{12}{*}{ MODELLING } & PA13 & 0.606 & 0.912 & 0.924 & 0.505 \\
\hline & PA14 & 0.685 & & & \\
\hline & PA15 & 0.649 & & & \\
\hline & PA16 & 0.669 & & & \\
\hline & PA17 & 0.701 & & & \\
\hline & PA18 & 0.785 & & & \\
\hline & PA19 & 0.792 & & & \\
\hline & PA20 & 0.751 & & & \\
\hline & PA21 & 0.781 & & & \\
\hline & PA22 & 0.721 & & & \\
\hline & PA23 & 0.709 & & & \\
\hline & PA24 & 0.649 & & & \\
\hline
\end{tabular}


Table 2. Discriminant validity of the Variables

\begin{tabular}{|c|c|c|c|c|c|}
\hline Variable & Mean & VIF & Attitude & Encouragement & Modelling \\
\hline Attitude & 3.83 & & & & \\
\hline Encouragement & 3.88 & 2.36 & 0.873 & & 0.814 \\
\hline Modelling & 3.81 & 2.36 & 0.879 & & \\
\hline
\end{tabular}

Table 3. Direct Effect Result of the Hypothesis Testing

\begin{tabular}{|c|c|c|c|c|c|c|c|}
\hline Variable & Beta & Standard Error & T Values & P Values & LL (5\%) & UL (95\%) & Result \\
\hline Encouragement -> Attitude & 0.483 & 0.056 & 8.609 & 0.000 & 0.366 & 0.586 & Accepted \\
\hline Modelling -> Attitude & 0.463 & 0.057 & 8.140 & 0.000 & 0.362 & 0.583 & Accepted \\
\hline
\end{tabular}

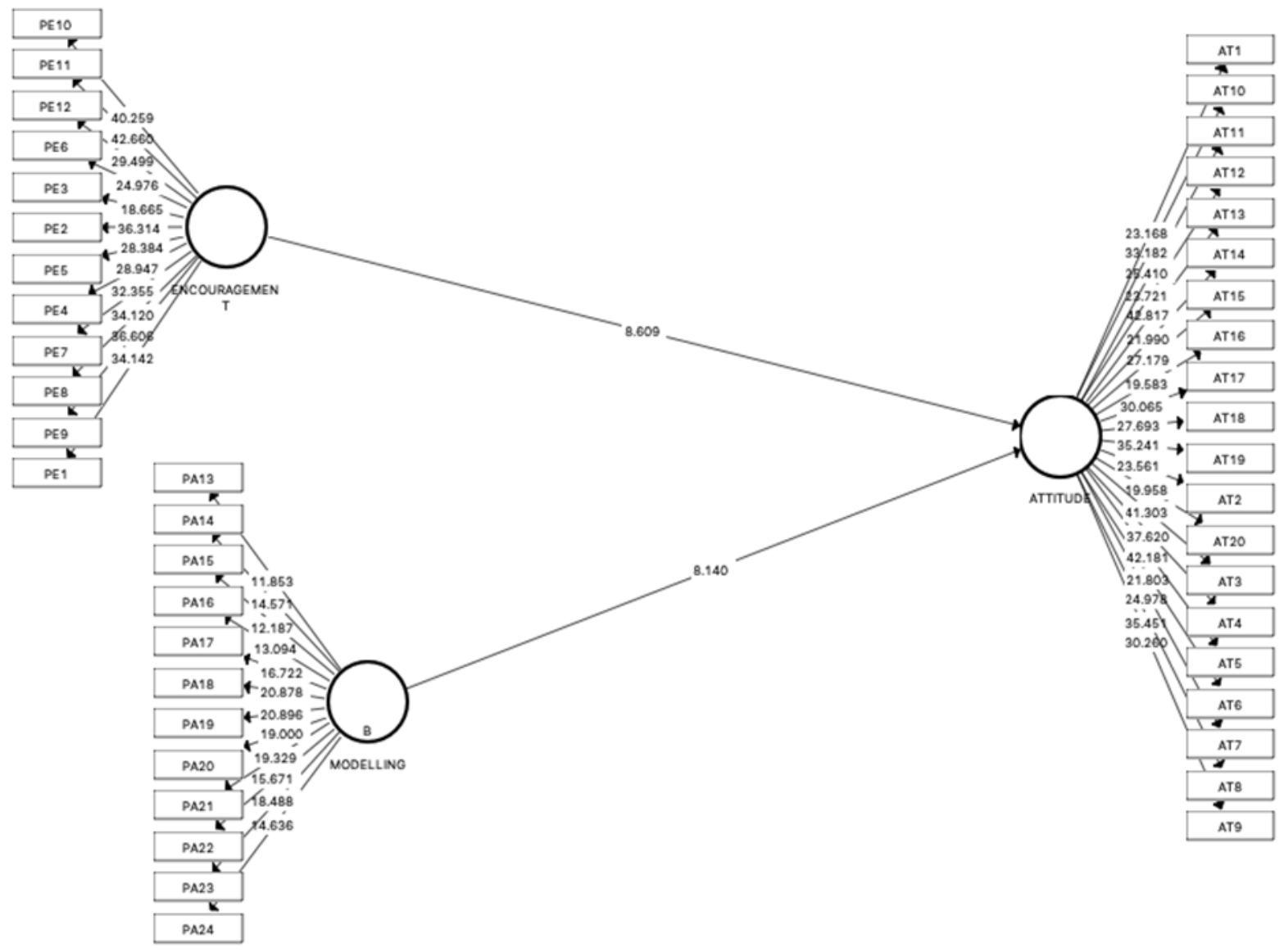

Figure 1. Structural Model of the study

\subsection{Structural Model}

In examining the structural model $\mathrm{R}^{2}$, beta and the corresponding t-values are involved [33]. To get the t-values, a bootstrapping process with 500 resamples was applied. T-value is considered very important in accepting or rejecting a hypothesis.

First, we look at the predictors of attitude towards reading. Parental encouragement $(\beta=0.48, p<0.01)$ is positively related to attitude towards reading, Positive Modelling ( $\beta=0.463 p<0.01)$ is positively related to attitude towards reading, both explaining $78.6 \%$ of variance on attitude towards reading. As shown in the table 3.

\section{Discussion}

In this study, the examination of children's attitudes towards reading was explored from the perspective of social constructivism in which parental involvement and attitudes as social constructs are seen as deeply rooted in the social context in which reading is meaningful [36-38]. The findings of the present research indicate significant impact of parental encouragement, positive modelling on cycle 1 children's attitudes towards reading. Few major findings arise from this study.

The results of this study suggest that parental involvement in reading English and strategies can increase fourth-grade students' attitude towards reading. The 
students who received extra help from their parents produce significantly positive attitude towards reading when compared to the students who did not receive additional help at home. Results of this study support the research that suggests that, when parents highly concerned about their children to read, they can become active and resourceful, and a positive attitude towards reading establishes. This study has extended the approach of Alazri [25] by examining the two separate dimension of parental involvement on the attitude towards reading. Both the dimensions have positive impact on the attitude towards reading among cycle one students of Basic Education in the Sultanate of Oman. But encouragement $(\mathrm{t}=8.60)$ has more positive impact on the attitude towards reading than positive model $(\mathrm{t}=8.14)$. The findings show the parents encouragement improves the reading attitude as when they encourage their children to read about social events, contents of products, e-books, advertisement boards and poems. The findings of the study are consistent with the findings of Kalayci and Oz [26]. They reported the positive impact of parental involvement on the academic and psychological achievements of the students.

This study contributes to the body of knowledge in many ways, firstly, to the authors' knowledge as this is the only study conducted among cycle one students in the Sultanate of Oman. Previously, Alazri [25] conducted a research on parental involvement and tested the role of parents in encouraging the children to read but in his study was on the validation of two dimensions of parental involvement. Our study has extended the approach of Alazri [25] by testing the effect of parental involvement on the attitude towards reading. Secondly, this study has extended the body of knowledge by expanding the scope of attitude towards reading in English in the context of Middle East, where first language is Arabic and the ability of reading and writing English is very low. Also, this study has influenced the parents and teachers to motivate the children to read, as this strategy can help them to increase their interest in reading books. Lastly, this research helps the school administration to improve the student's ability by arranging small social events where parents of the students show their participation and involvement in improving their children's' academic and psychological performance.

Similar to other studies this research also has some limitations and recommendations for future studies. First of all, this study was cross sectional in design, due to time constraint it was difficult to conduct the study in multiple phases. Perhaps for future research it is suggested to conduct the research in longitudinal design. There are number of factors that can be the outcome of attitude towards reading. It is recommended to extend the research by examining those factors such as academic performance, reading ability, psychological development and other pertinent factors.

\section{Conclusions}

This study was conducted to examine the impact of parental involvement on the attitude towards reading English. Two-dimensional approach of parental involvement was used to examine the effect on attitude towards reading English. The results show positive impact of parental involvement. When the parents encourage their children to read English, it improves not only their attitude towards reading but also improves their overall knowledge and perception. Parents should bring their children to libraries, social events and give them books as gifts so that they can develop a good English reading habit.

\section{REFERENCES}

[1] Cheng, J. Research on the Cultivation of Infants and Young Children'Early Reading Habits in Two-Child Family Environment. In 3rd International Conference on Economics and Management, Education, Humanities and Social Sciences (EMEHSS 2019). 2019. Atlantis Press.

[2] Gambrell, L.B., Getting students hooked on the reading habit. The Reading Teacher, 2015. 69(3): p. 259-263.

[3] Blair, C., et al., Multiple aspects of self-regulation uniquely predict mathematics but not letter-word knowledge in the early elementary grades. Developmental psychology, 2015. 51(4): p. 459.

[4] Kolomeichuk, S.N., et al., The influence of chronotype on the academic achievement of children and adolescentsevidence from Russian Karelia. Biological Rhythm Research, 2016. 47(6): p. 873-883.

[5] McGeown, S.P., et al., The relationship between young children's enjoyment of learning to read, reading attitudes, confidence and attainment. Educational Research, 2015. 57(4): p. 389-402.

[6] Kovachy, V.N., et al., Reading abilities in school-aged preterm children: a review and meta-analysis. Developmental Medicine \& Child Neurology, 2015. 57(5): p. 410-419.

[7] McClure, E.L. and S.K. Fullerton, Instructional interactions: Supporting students' reading development through interactive read-alouds of informational texts. The Reading Teacher, 2017. 71(1): p. 51-59.

[8] McGeown, S.P., et al., Understanding children's reading activities: Reading motivation, skill and child characteristics as predictors. Journal of research in reading, 2016. 39(1): p. 109-125.

[9] Simon, M., et al., Spelling, Reading Abilities and Speech Perception in Deaf Children with a Cochlear Implant. Scientific Studies of Reading, 2019: p. 1-15.

[10] Wigfield, A., J.R. Gladstone, and L. Turci, Beyond cognition: Reading motivation and reading comprehension. Child development perspectives, 2016. 10(3): p. 190-195.

[11] Progress in International Reading Literacy Study International Report. 2001.

[12] Alexander, J.E. and R.C. Filler, Attitudes and reading. 1976: 
Newark, Del.: International Reading Association.

[13] Saito, Y., T.J. Garza, and E.K. Horwitz, Foreign language reading anxiety. The modern language journal, 1999. 83(2): p. 202-218.

[14] Beck, J.E. Using response times to model student disengagement. in Proceedings of the ITS2004 Workshop on Social and Emotional Intelligence in Learning Environments. 2004.

[15] McKenna, M.C., D.J. Kear, and R.A. Ellsworth, Children's attitudes toward reading: A national survey. Reading research quarterly, 1995: p. 934-956.

[16] Lim, H.J., M. Bong, and Y.-K. Woo, Reading Attitude as a Mediator between Contextual Factors and Reading Behavior. Teachers College Record, 2015. 117(1): p. n1.

[17] Ozturk, G., S. Hill, and G.C. Yates, Girls, boys and early reading: parents' gendered views about literacy and children's attitudes towards reading. Early Child Development and Care, 2016. 186(5): p. 703-715.

[18] Conradi, K., et al., Measuring adolescents' attitudes toward reading: A classroom survey. Journal of Adolescent \& Adult Literacy, 2013. 56(7): p. 565-576.

[19] Skouteris, H., B. Watson, and J. Lum, Preschool children's transition to formal schooling: The importance of collaboration between teachers, parents and children. Australasian Journal of Early Childhood, 2012. 37(4): p. 78-85.

[20] Faires, J., W.D. Nichols, and R.J. Rickelman, Effects of parental involvement in developing competent readers in first grade. Reading Psychology, 2000. 21(3): p. 195-215.

[21] Fishel, M. and L. Ramirez, Evidence-based parent involvement interventions with school-aged children. School psychology quarterly, 2005. 20(4): p. 371.

[22] Bakker, J., E. Denessen, and M. Brus-Laeven, Socio-economic background, parental involvement and teacher perceptions of these in relation to pupil achievement. Educational Studies, 2007. 33(2): p. 177-192.

[23] Kim, E.M., et al., Parent Involvement and Family-School Partnerships: Examining the Content, Processes, and Outcomes of Structural versus Relationship-Based Approaches. CYFS Working Paper No. 2012-6. Nebraska Center for Research on Children, Youth, Families and Schools, 2012.

[24] Funge, S.P., D.J. Sullivan, and K. Tarter, Promoting positive family interactions: Evaluating a free early childhood book distribution program. Early Childhood Education Journal, 2017. 45(5): p. 603-611.

[25] ALazri, S.N.S., Developing a Questionnaire for Assessing Parental Involvement in Reading in Sultanate of Oman. International Journal of Language and Linguistics, 2013. $6(1)$.

[26] Kalayci, G. and H. Oz, Parental Involvement In English Language Education: Understanding Parents' Perceptions. International Online Journal of Education and Teaching, 2018. 5(4): p. 832-847.

[27] Hoover-Dempsey, K.V. and H.M. Sandler, Parental involvement in children's education: Why does it make a difference? Teachers college record, 1995.

[28] Paulson, S.E., Relations of parenting style and parental involvement with ninth-grade students' achievement. The Journal of Early Adolescence, 1994. 14(2): p. 250-267.

[29] Kaplan Toren, N., Multiple dimensions of parental involvement and its links to young adolescent self-evaluation and academic achievement. Psychology in the Schools, 2013. 50(6): p. 634-649.

[30] McKenna, M.C. and D.J. Kear, Measuring attitude toward reading: A new tool for teachers. The reading teacher, 1990. 43(9): p. 626-639.

[31] Khalid, J., et al., Multiple dimensions of emotional intelligence and their impacts on organizational commitment and job performance. International Journal of Ethics and Systems, 2018. 34(2): p. 221-232.

[32] Ringle, C.M., S. Wende, and A. Will, SmartPLS 2.0 (beta). 2005, Hamburg.

[33] Hair, J., Joe, et al., Partial least squares structural equation modeling (PLS-SEM) An emerging tool in business research. European Business Review, 2014. 26(2): p. 106-121.

[34] Al-Gahtani, S.S., G.S. Hubona, and J. Wang, Information technology (IT) in Saudi Arabia: Culture and the acceptance and use of IT. Information \& Management, 2007. 44(8): p. 681-691.

[35] Fornell, C. and D.F. Larcker, Structural equation models with unobservable variables and measurement error: Algebra and statistics. Journal of marketing research, 1981: p. 382-388.

[36] Battle-Bailey, L., Review of research: Interactive homework for increasing parent involvement and student reading achievement. Childhood Education, 2004. 81(1): p. 36-40.

[37] Boyle, A., J. Hanafin, and M. Flynn, Parental involvement: Irish travellers and early years education. 2018.

[38] Dorsch, T.E., et al., Stakeholders' perceptions of parent involvement in young adults' intercollegiate athletic careers: Policy, education, and desired outcomes. Journal of Issues in Intercollegiate Athletics, 2016. 9: p. 124-141. 